\title{
Protección de datos personales a través del secreto profesional en el ámbito de la Administración Sanitaria Local
}

\author{
María Dolores Calvo Sánchez \\ Profesora de Derecho Sanitario \\ Universidad de Salamanca
}

Sumario: I. INTRODUCCIÓN. II. CONCEPTOS Y DEFINICIONES. III. TRATAMIENTO JURÍDICO. Normativa Internacional. Normativa Comunitaria. Normativa Nacional. IV. LÍMITES AL DERECHO.

\section{INTRODUCCIÓN}

La necesidad de protección de los datos personales en el ámbito sanitario, como todos sabemos, es objeto de especial trato por cuanto viene a tutelar un derecho fundamental que nuestra Constitución del 78 proclama: la intimidad de las personas, y quizás de todos los derechos relativos a la salud que el legislador otorga al ciudadano, sea el secreto exigido a los profesionales sanitarios, el que mayor vínculo posee a esa merecida protección, ya que sin duda constituye su existencia una importante trascendencia para el correcto funcionamiento de las relaciones entre el profesional sanitario, debiendo acotar el estudio al Médico-Enfermero y al Usuario/Paciente del Sistema de Salud (Ciudadano), al conformar un vínculo de confianza necesario cuya presencia en todas las actuaciones se manifiesta como esencial, máxime ante la proximidad o cercanía social que supone el ámbito de la Administración Sanitaria Local.

La oportunidad del momento para abordar el tema se presenta desde la actualidad mas próxima, la reforma legislativa ${ }^{1}$ en materia de información sanitaria, el tratamiento jurídico estricto hacia la protección de datos de carácter personal ${ }^{2}$, la incorporación a la praxis diaria de nuevas tecnologías como la informática, la concepción del trabajo en equipo, las políticas de humanización de la asistencia sanitaria, junto al reconocimiento legal de los profesionales de la salud con competencias definidas por ley, hace que estudiemos el secreto profesional como una necesidad de conocer y entender, para

\footnotetext{
1 Entre otras: - Ley 41/2002, de 14 de noviembre, básica reguladora de la autonomía del paciente y de derechos y obligaciones en materia de información y documentación

- Ley 16/2003, de 28 de mayo, de cohesión y calidad del Sistema Nacional de Salud.

- Ley 44/2003, de 21 de noviembre, de ordenación de las profesiones sanitarias

${ }^{2}$ Ley Organica 15/1999, de 13 de diciembre, de Protección de Datos de Carácter Personal
} 
poder mas tarde aplicar y observar, sobre un tema donde la bibliografía específica es escasa.

El hombre gusta de su intimidad pero la necesidad de acudir a otros para paliar sus deficiencias, como bien pudiera ser la enfermedad, hace que proteja sus intereses a través de mecanismos garantes de sus derechos. Así el secreto profesional surge como imperante necesidad de que se preserve una parcela de la persona que se estima debe ser reservada y que de vulnerarse produciría un quebranto al interesado y/o a terceros, entendiendo éstos, como personas de buena fe con intereses legítimos.

Los profesionales sanitarios consideran (macroencuesta realizada por el Prof. Garrido Peña) que el secreto profesional constituye un problema preocupante dentro de su actividad profesional, detectar las deficiencias muchas veces estructurales, tomar conciencia de la relevancia que tienen los datos sanitarios personales y solucionarlo desde la formación parece objetivo prioritario. En este sentido, estudios doctorales como el de HEITZMAN ${ }^{3}$ referidos al secreto médico revelan que existe falta de formación sobre el tema, ya que se trivializa sobre la intimidad ajena de manera inconsciente.

\section{CONCEPTOS Y DEFINICIONES}

Resulta necesario abordar ciertos conceptos y definiciones al fin de homologar nociones. Entendemos por secreto «lo que cuidadosamente se tiene reservado y oculto» (RAE), calificándolo de profesional cuando la materia en cuestión es perteneciente o relativa a la profesión, en nuestro caso «profesional sanitario». A partir de la Ley 44/2003, identificamos a los profesionales de la salud, aquellos tipificados en la Ley de Ordenación de Profesionales de la Salud ${ }^{4}$, cuyo tenor establece a los licenciados y diplomados universitarios (por escaso tiempo ya que la incorporación de las Titulaciones al Espacio de Educación Superior Europeo, pasarán a denominarse graduados): Médicos, Farmacéuticos, Veterinarios, Odontólogos, Enfermeros, Fisioterapeutas, Ópticos-Optometristas, Logopedas, Terapeutas Ocupacionales, Dietistas Nutricionistas, Podólogos. Parece claro que la exigencia de secreto profesionales recaiga a priori sobre estos sanitarios, dejando la protección de datos personales del resto del personal sanitario (no profesional), a merced de la confidencialidad.

\footnotetext{
${ }^{3}$ Heitzman, T., «El secreto médico: actitudes y toma de decisiones en la práctica clínica», Tesis Doctoral, Universidad Complutense, 2000.

${ }^{4}$ Ley 44/2003 de Ordenación de Profesiones Sanitarias, Art. 2.1: «de conformidad con el artículo 36 de la Constitución y a los efectos de esta ley, son profesionales sanitarios, titulados y regulados, aquéllos cuya formación pregraduada o especializada se dirige específicamente y fundamentalmente a dotar a los interesados de conocimientos, habilidades y actitudes propias de la atención de salud y están organizados en colegios profesionales oficialmente reconocidos por los poderes públicos de acuerdo con lo previsto en la normativa específicamente aplicable.»
} 
PROTECCIÓN DE DATOS PERSONALES A TRAVÉS DEL SECRETO PROFESIONAL...

La figura del secreto en sanidad se ha ido gestando a lo largo de la historia, naciendo como un acto de simple discreción propio a cualquier trabajo y adquiriendo prontamente la relevancia de secreto en sentido estricto. El propio Hipócrates ${ }^{5}$ establece el deber del secreto, como conducta inherente a la condición sanitaria.

Util también nos resultará conocer lo que se entiende por Usuario ${ }^{6}$, concepto legal que responde a «la persona que utiliza los servicios sanitarios de educación y promoción de la salud, de prevención de enfermedades y de información sanitaria», sería pues perfectamente identificable con el ciudadano que no padece patología alguna en principio y que utiliza las prestaciones que le otorga la Administración Local. Sin embargo paciente ${ }^{7}$ será entendido como «persona que requiere asistencia sanitaria y está sometida a cuidados profesionales para el mantenimiento o recuperación de la salud», quedando genéricamente excluido por cuestión competencial de ámbito que nos ocupa, ya que son escasas y excepcionales las Administraciones Locales que poseen atención especializada básicamente prestada en instituciones cerradas u hospitalarias.

Respecto al dato y su tratamiento conviene saber lo que el legislador redacta, así entendemos por:

Datos Personales ${ }^{8}:$ «la expresión "datos personales" abarca cualquier información relativa a un individuo identificado o identificable. Un individuo no se considerará "identificable" si la identificación requiere una cantidad de tiempo y de medios no razonables. En los casos en que el individuo no sea inidentificable, los datos son denominados anónimos».

Datos Médicos 9: «la expresión "datos médicos" se refiere a todos los datos personales relativos a la salud de un individuo. Se refiere también a los datos que tengan una clara y estrecha relación con la salud y los datos genéticos».

Datos Genéticos ${ }^{10}:$ :Se refiere a todos los datos, cualquiera que sea su clase, relativos a las características hereditarias de un individuo o al patrón hereditario de tales características dentro de un grupo de individuos emparentados».

\footnotetext{
5 Juramento Hipocrático ( S.V a.c.) «Respetaré los secretos que me fueren confiados en todo aquello que con ocasión o a consecuencia de mi profesión pudiera haber conocido y no debe ser revelado».

6 Art. 3 de la Ley 41/2002.

7 Supra cit.

${ }^{8}$ Recomendación Europea n. R (97) 5, de 13 de febrero de 1997.

9 Opus cit. 5.

${ }^{10}$ Opus cit. supra.
} 
Datos de carácter Personal ${ }^{11}$ : "Cualquier información concerniente a personas físicas identificadas o identificables».

Información Clínica ${ }^{12}$ : «todo dato, cualquiera que sea su forma, clase o tipo, que permite adquirir o ampliar conocimiento sobre el estado físico y la salud de una persona o la forma de preservarla, cuidarla, mejorarla o recuperarla».

Documentación Clínica ${ }^{13}$ : «el soporte de cualquier tipo o clase que contiene un conjunto de datos e informaciones de carácter asistencial»

Historia Clínica: «conjunto de documentos que contienen los datos, valoraciones e informaciones de cualquier índole, sobre la situación y evolución clínica de un paciente a lo largo del proceso asistencial».

Fichero 14: "Todo conjunto organizado de datos de carácter personal, cualquiera que fuera la forma o modalidad de su creación, almacenamiento, organización y acceso».

Tratamiento de Datos ${ }^{15}$ : «Operaciones y procedimientos técnicos de carácter automatizado o no, que permitan la recogida, grabación, conservación, elaboración, modificación, bloqueo y cancelación, así como las cesiones de datos que resulten de comunicaciones, consultas, interconexiones y transferencias».

Responsable del fichero o tratamiento ${ }^{16}$ : «Persona física o jurídica, de naturaleza pública o privada, u órgano administrativo, que decida sobre la finalidad, contenido y uso del tratamiento».

Afectado o Interesado ${ }^{17}$ : «Persona física titular de los datos que sean objeto del tratamiento a que se refiere el tratamiento de datos».

Procedimiento de Disociación ${ }^{18}$ : «Todo tratamiento de datos personales de modo que la información que se obtenga no pueda asociarse a persona identificada o identificable».

Quizás no estén todos los conceptos o definiciones existentes sobre la materia objeto, pero sí los necesarios para comprender de manera inequívo-

\footnotetext{
11 Ley Orgánica 15/1999, art. 3. a)

12 Ley 41/2002, art. 3.

13 Art. 3 de la Ley 41/2002, de 14 de noviembre, básica reguladora de la autonomía del paciente y de los derechos y obligaciones en materia de información y documentación clínica.

14 Ley Orgánica 15/1999, art. 3. b).

15 Ley Orgánica 15/1999, art. 3. c).

16 Ley Orgánica 15/1999, art. 3. d).

17 Ley Orgánica 15/1999, art. 3. e).

18 Ley Orgánica 15/1999, art. 3. f).
} 
PROTECCIÓN DE DATOS PERSONALES A TRAVÉS DEL SECRETO PROFESIONAL...

ca y con mayor pureza todo lo formulado respecto a los datos sanitarios considerados confidenciales y sujetos a secreto profesional, que a lo largo del estudio vamos a tratar y que inevitablemente aludiremos de manera directa o indirecta.

\section{TRATAMIENTO JURÍDICO}

A pesar de que no exista una ley específica que regule el Secreto Profesional, muchas son las normas de las que deducimos su obligatoriedad, siendo legislado como derecho de los usuarios y a sensu contrario como deber del profesional. Estudiando el ordenamiento jurídico, llegaremos a conocer lo que la sociedad nos impone y, por lo tanto, el comportamiento que espera de los profesionales de la salud.

Tengamos claro que el deber de secreto, trasciende la esfera de la relación personal, la consagrada historia clínica en soporte papel y la incorporación de la tecnología informática, forman parte indispensable de las actuaciones no sólo asistenciales propiamente dichas, sino de las duras tareas burocráticas inherentes al correcto y completo desarrollo profesional, y es esta perspectiva multifactorial la que debe presidir las debidas cautelas, respecto al deber de preservar los datos de carácter personal.

El legislador nos impone un comportamiento que se debe asumir, pero parece obvio afirmar que para cumplir el mandato hay que conocerlo y es precisamente al descubrimiento del contenido de las leyes a lo que se refiere este apartado, desgranando el contenido imperativo a través de la jerarquía de la norma.

\section{Normativa Internacional}

El legislador internacional concede especial protección a la vida privada de las personas y de sus familias, y si existe un sector social donde la intimidad se halle impregnado en todas sus actuaciones, ése es sin duda el sanitario. Así pues, el legislador español deberá hacer suya esta recomendación y mantener lo más actual posible este mandato en todos los ámbitos de los ciudadanos, sin olvidar de modo alguno el sanitario. Este precepto deberá presidir todos los contenidos e intenciones legislativas, pudiendo ser exigido legítimamente por la ciudadanía y los profesionales en su caso.

La Declaración Universal de Derechos Humanos, proclamada por la Asamblea General de las Naciones Unidas el 10 de diciembre de 1948, establece ${ }^{19}$ :

19 Art. 12 de la Declaración Universal de Derechos Humanos. 
«Nadie será objeto de injerencias arbitrarias en su vida privada, su familia, su domicilio o su correspondencia, ni de ataques a su honra o su reputación. Toda persona tiene derecho a la protección de la ley contra tales injerencias».

\section{Normativa Comunitaria}

La normativa comunitaria, igualmente necesaria su referencia por cuanto España es miembro de pleno derecho de la Comunidad Europea, establece el derecho a la intimidad y a los mecanismos garantes necesarios para que no sufra la persona injerencia alguna en cualquier ámbito donde se trate sus datos personales, incluyendo la sanidad con especial celo.

El origen de la preservación de la intimidad sobre datos automatizados en el ámbito comunitario, se halla en la Resolución 509 de la Asamblea del Consejo de Europa de 1968, sobre «Los Derechos Humanos y los logros Científicos y Técnicos», que junto a la Ley del Land de Hesse de 17 de octubre de 1970 de Alemania, la Datalag Sueca en 1973, la Privacy Act Estadounidense en 1974, la Constitución de Portugal de 1976, la Ley de Protección de Datos Francesa de 1978, constituyeron el punto de partida y apoyo de la promulgación del Convenio 108 del Consejo de Europa firmado en 1981 y ratificado por España el 27 de enero de $1984{ }^{20}$ y por ello de obligado cumplimiento.

La Directiva Comunitaria 95/46/CE, relativa a la protección de las personas físicas, en lo que respecta al tratamiento de datos personales y a la libre circulación de estos datos, como respuesta de precisión y aplicación del Convenio de 28 de enero de 1981 del Consejo de Europa, obliga de manera explícita al legislador español a adaptar la ley interna vigente al contenido de la directiva.

«Los Estados miembros garantizarán... en particular el derecho a la intimidad en lo que respecta al tratamiento de datos personales.» (art. 1).

Igualmente es consciente el responsable europeo al redactar la Recomendación (97) 5, de que el progreso de la ciencia médica depende en buena medida de la disponibilidad de datos médicos sobre individuos y que es deseable regular la recogida y procesamiento de datos médicos, salvaguardar la confidencialidad y la seguridad de los datos personales relativos a la salud y asegurar que se emplean de acuerdo con los derechos y libertades fundamentales del individuo, y en particular con el derecho a la intimidad.

Establece igualmente las pautas a seguir sobre la recogida y procesamiento e información de datos médicos o genéticos, siempre con consentimiento ${ }^{21}$

\footnotetext{
${ }^{20}$ Convenio $\mathrm{n}^{\mathrm{o}} 108$ del Consejo de Europa para la Protección de las personas con respecto al tratamiento automatizado de datos de carácter personal, B.O.E. de 15 de noviembre de 1984.

${ }^{21}$ Consentimiento (Principio 6): «6.1. Al solicitar el consentimiento del afectado, éste debe ser libre, expreso e informado.
} 
PROTECCIÓN DE DATOS PERSONALES A TRAVÉS DEL SECRETO PROFESIONAL...

del afectado, representante legal o la autoridad, persona u órgano previsto o lo que la ley disponga, en términos y condiciones de seguridad y conservación que igualmente se prevé conteniendo su salvaguarda.

\section{Normativa Nacional}

El tratamiento del ordenamiento jurídico español vigente nos hace conocer que el secreto profesional constituye una obligación ineludible para el sanitario, deducible esta afirmación del contenido de leyes orgánicas o normas reglamentarias, abundantes en número y en clara consonancia con lo preceptuado en la Constitución Española del $78^{22}$, donde esta figura jurídica es objeto de mandato de regulación específica, teniendo que apuntar una vez más, que es asignatura pendiente del legislador hasta la fecha ${ }^{23}$.

Leyes orgánicas protectoras de la intimidad ${ }^{24}$ vienen tratando a los datos personales sobre la salud de forma especial, intentan dar la importancia y reconocimiento, que éstos tienen sobre la esfera de intimidad de toda persona. Queda claro que para recabar, tratar o ceder este tipo de datos sólo podrán los profesionales sanitarios sujetos a secreto profesional, dejando aquellas otras personas (resto del personal del ámbito sanitario, no profesional) ${ }^{25}$ bajo el sometimiento de confidencialidad. Impone el legislador penal fuertes penas a la vulneración o incumplimiento del secreto « El profesional que, con incumplimiento de sigilo o reserva, divulgue los secretos de otra persona, será castigado con la pena de prisión de uno a cuatro años, multa de doce a veinticuatro meses e inhabilitación especial para dicha profesión por tiempo de

6.2. Los resultados de cualquier análisis genético se deben formular dentro de los límites de los objetivos de la consulta, el diagnostico o tratamiento para el que se obtuvo el consentimiento.

6.3. Cuando se trate de procesar datos médicos de una persona legalmente incapacitada que es incapaz de una decisión libre, y cuando la ley nacional no le permita actuar en su propia representación, es preciso obtener el consentimiento de la persona legalmente habilitada para actuar en interés de éste, o de la autoridad o persona u órgano designados por ley con este fin.

Si de acuerdo con el principio 5.5 ( $\mathrm{si}$ el afectado es una persona legalmente incapacitada, incapaz de tomar una decisión libre y consciente, y la ley nacional no le permite actuar en su propia representación, la información se facilitará a la persona reconocida como legalmente habilitada para actuar en interés del afectado. Si una persona legalmente incapacitada es capaz de entender, se le debe informar antes de recoger o procesar sus datos), una persona legalmente incapacitada ha sido informada de la intención de recoger o procesar sus datos médicos, sus deseos deben tenerse en cuenta, a menos que la ley nacional disponga otra cosa».

22 Art. 18.1 C.E.; art. 24.2 in fine C.E.

${ }^{23}$ Art. 20.1 in fine C.E. : «La ley regulará el derecho a la cláusula de conciencia y al secreto profesional en el ejercicio de las libertades».

${ }^{24}$ L.O. 1/1982, de protección civil del derecho al honor, la intimidad personal y familiar y a la propia imagen: L.O. 15/1999 de protección de datos de carácter personal.; L.O. 10/1995, del Código Penal.

${ }^{25}$ Ley 14/86, General de Sanidad, art.10.3. 
dos a seis años» ${ }^{26}$, así como respecto a la violación documental a través de los artículos 197 y 198 del Código Penal ${ }^{27}$.

Leyes ordinarias como la Ley General de Sanidad ${ }^{28}$, Ley Básica Reguladora de la Autonomía y Documentación clínica ${ }^{29}$, Ley de Cohesión y Calidad del S.N.S. ${ }^{30}$, Ley de Extracción y Trasplante de órganos humanos ${ }^{31}$, Ley sobre Técnicas de Reproducción Asistida ${ }^{32}$, Ley de Prevención de Riesgos Laborales ${ }^{33}$, Ley de Ordenación de Profesiones Sanitarias ${ }^{34}$, Ley de refor-

\begin{abstract}
26 Art. 199.2 Código Penal.
27 Art. 197 C.P.: 1. El que, para descubrir los secretos o vulnerar la intimidad de otro, sin su consentimiento, se apodere de sus papeles, cartas, mensajes de correo electrónico o cualesquiera otros documentos o efectos personales o intercepte sus telecomunicaciones o utilice artificios técnicos de escucha, transmisión, grabación o reproducción del sonido o de la imagen, o de cualquier otra señal de comunicación, será castigado con las penas de prisión de uno a cuatro años y multa de doce a veinticuatro meses.
\end{abstract}

2. Las mismas penas se impondrán al que, sin estar autorizado, se apodere, utilice o modifique, en perjuicio de tercero, datos reservados de carácter personal o familiar de otro que se hallen registrados en ficheros o soportes informáticos, electrónicos o telemáticos, o en cualquier otro tipo de archivo o registro público o privado. Iguales penas se impondrán a quien, sin estar autorizado, acceda por cualquier medio a los mismos y a quien los altere o utilice en perjuicio del titular de los datos o de un tercero.

3. Se impondrá la pena de prisión de dos a cinco años si se difunden, revelan o ceden a terceros los datos o hechos descubiertos o las imágenes captadas a que se refieren los números anteriores.

Será castigado con las penas de prisión de uno a tres años y multa de doce a veinticuatro meses, el que, con conocimiento de su origen ilícito y sin haber tomado parte en su descubrimiento, realizare la conducta descrita en el párrafo anterior.

4. Si los hechos descritos en los apartados 1 y 2 de este Artículo se realizan por las personas encargadas o responsables de los ficheros, soportes informáticos, electrónicos o telemáticos, archivos o registros, se impondrá la pena de prisión de tres a cinco años, y si se difunden, ceden o revelan los datos reservados, se impondrá la pena en su mitad superior.

5. Igualmente, cuando los hechos descritos en los apartados anteriores afecten a datos de carácter personal que revelen la ideología, religión, creencias, salud, origen racial o vida sexual, o la víctima fuere un menor de edad o un incapaz, se impondrán las penas previstas en su mitad superior.

6. Si los hechos se realizan con fines lucrativos, se impondrán las penas respectivamente previstas en los apartados 1 al 4 de este Artículo en su mitad superior. Si además afectan a datos de los mencionados en el apartado 5, la pena a imponer será la de prisión de cuatro a siete años».

«Art. 198 C.P.: La autoridad o funcionario público que, fuera de los casos permitidos por la Ley, sin mediar causa legal por delito, y prevaliéndose de su cargo, realizare cualquiera de las conductas descritas en el Artículo anterior, será castigado con las penas respectivamente previstas en el mismo, en su mitad superior y, además, con la de inhabilitación absoluta por tiempo de seis a doce años».

${ }^{28}$ Ley 14/1986, de 25 de abril, General de Sanidad

${ }^{29}$ Ley 41/2002, de 14 de noviembre, básica reguladora de la autonomía del paciente y de derechos y obligaciones en materia de información y documentación clínica.

${ }^{30}$ Ley 16/2003, de 28 de mayo, de Cohesión y Calidad del SNS.

31 Ley 30/1979, de 27 de octubre, sobre Extracción y Trasplante de órganos.

${ }^{32}$ Ley 45/2003, de 21 de noviembre, sobre Técnicas de Reproducción Asistida.

${ }^{33}$ Ley 31/1995, de 8 de noviembre, de Prevención de Riesgos Laborales.

${ }^{34}$ Ley 44/2003, de 21 de noviembre, de Ordenación de Profesiones Sanitarias. 
PROTECCIÓN DE DATOS PERSONALES A TRAVÉS DEL SECRETO PROFESIONAL...

ma de la Función Pública ${ }^{35}$, Ley de Estatuto Marco del personal estatutario de los servicios de salud ${ }^{36}$, construyen un verdadero cuerpo legal sanitario, donde la exigencia de salvaguardar los datos sanitarios personales bajo la forma de secreto constituye una garantía para el ciudadano.

El ámbito Deontológico cobra en este tema especial importancia, por cuanto los sanitarios poseen códigos de los más completos y exigentes en comparación con profesiones afines, propicia no sólo el sigilo y la reserva sino la discreción como conducta apropiada, intentando proteger a la vez los intereses del usuario, fin último y noble de todo sanitario.

\section{LÍMITES AL DERECHO}

Pero el Secreto Profesional como cualquier deber en un sistema democrático no es absoluto, pues existen límites que son marcados por el interés general (salud pública), por el interés del propio del usuario (estado de necesidad/urgencia), de terceros en situaciones/intereses legítimos, o cuando así lo disponga una ley.

El Tribunal Constitucional viene manteniendo una postura doctrinal basada en la «proporcionalidad» respecto a otros bienes jurídicos susceptibles de igual tratamiento jurídico, manteniendo que ante posibles colisiones, deberá valorarse cual es proporcionalmente más relevante (v.gr.: derecho a la vida sobre el derecho a la intimidad).

Como garantía de cumplimiento establece el legislador fuertes sanciones indemnizatorias (hasta seiscientos mil euros), multas (veinticuatro meses), privación de libertad (hasta cuatro años de prisión) y separación del ejercicio profesional (inhabilitación hasta seis años). Tutelado por el Sistema Judicial o instituciones creadas «ad hoc» como la Agencia de Protección de Datos.

Importante aportación haríamos con este artículo si inducimos a la reflexión individual y recordáramos colectivamente que un valor que los sanitarios abanderan es la discreción, sancta sanctorum del Secreto Profesional.

«Porque una herida se vendal una injuria se perdona/ pero quien revela un secreto no tiene esperanza» (Eclesiástico, 27,23 y 24).

${ }^{35}$ Ley 30/1984, de 8 de agosto, reforma de la Función Pública.

${ }^{36}$ Ley 55/2003, de 16 de diciembre, del Estatuto Marco del personal estatutario de los servicios de salud. 